\title{
Perspective Advices in the Management of Ovarian Hyperstimulation Syndrome
}

\author{
Aleksei Petrovich Petrenko ${ }^{1,2,3}$ and Camil Andreu Castelo Branco Flores ${ }^{1 *}$ \\ ${ }^{1}$ Institut Clinic of Gynecology, Obstetrics and Neonatology, Hospital Clinic-Institut d'Investigacions Biomediques August Pi i Sunyer (IDIBAPS), Spain \\ ${ }^{2}$ Department of Anesthesiology, Russian Federation 410017, Russia \\ ${ }^{3}$ Department of Anesthesiology and Critical Care, State Budgetary Healthcare Institution of Moscow Region MF Vladimirskiy Moscow's Regional Research \\ Clinical Institute, Moscow
}

Submission: July 12, 2019 ; Published: July 23, 2019

*Corresponding author: Camil Andreu Castelo Branco Flores, Institut Clinic of Gynecology, Obstetrics and Neonatology, Hospital Clinic-Institut d'Investigacions Biomediques August Pi i Sunyer (IDIBAPS), Spain

Abbreviatation: OHSS: Ovarian Hyperstimulation Syndrome; IAH: Intra-Abdominal Hypertension Syndrome; ACS: Abdominal Compartment Syndrome; IAP: Intra-Abdominal Pressure

\section{Mini Review}

The increasing availability around the world of in vitro fertilization helps many patients who would be otherwise unable to conceive; however, this procedure has also some disadvantages. Among them, the increased risk of ovarian hyperstimulation syndrome (OHSS) mainly related to the use of human chorionic gonadotropin in assisted reproduction. As the pathophysiology and clinical picture of severe OHSS and its associated organ dysfunction are almost identical to intra-abdominal hypertension syndrome (IAH) or abdominal compartment syndrome (ACS), the management of OHSS may be considered also from the perspective of an IAH condition [1,2]. The classic triad, including respiratory disorders, decrease in venous return, and restriction of internal perfusion is present both in severe OHSS and IAH patients. Several studies related specific indices of the intra-abdominal pressure (IAP) with varying degrees of OHSS [3-7]. According to these data, the condition of IAH Grade I in moderate OHSS and IAH Grade II-III in severe OHSS are present [8]. Therefore, if we accept the hypothesis that both syndromes are similar, then the principles of OHSS therapy should be consistent with those drawn on the treatment of IAH.

The typical picture of severe OHSS is a young asthenic woman in her first pregnancy with a tense, enlarged abdomen, often with postoperative scars on the anterior abdominal wall. In this description, several risk factors that reduce compliance of the abdominal wall (Cab) are recorded. The abdominal cavity, with its unique anatomy and physiology, has a sophisticated sensitivi ty to pressure and perfusion being the role of Cab one of the most important. While preserving the reserve of extensibility of the anterior abdominal wall intra-abdominal pressure (IAP) grows slowly, but when this reserve is consumed IAP grows exponentially with a characteristic clinic of internal organ perfusion disorders, including respiratory, renal-hepatic and, ultimately, multiple organ failure.

Surgical decompression is presently an alternative used in the treatment of severe OHSS. Some authors describe a significant improvement of the renal blood flow and an increase of the diuresis after paracentesis or culdocentesis [9-11]. This positive trend can be explained by the effect of a decrease in IAP secondary to fluid removal. However, in most cases, a significant decrease in IAP is only recorded after 2000 or more $\mathrm{ml}$ of ascites removal. Controversially, an improvement in renal blood flow and urinary function occurred with the removal of much lesser volumes of fluid [12]. These data suggest that the effect of paracentesis depend not on the volume of fluid removed, but rather on the effect of decompression itself. Nevertheless, currently criteria for performing paracentesis are complaints of shortness of breath, abdominal distension, abdominal pain, oliguria, and treatment failure, i.e. already developed multiple organ dysfunction. If OHSS is considered from the perspective of IAH syndrome, then early decompression, even in patients with a moderate form of OHSS, when ascites is not expressed, may be probably justified. 
The procedure of negative extra-abdominal pressure (NEXAP) is one of the future promising options for non-invasive treatment of IAH/ACS $[13,14]$. Scientific studies on the physiological effects of localized decompression began in 1959 with a method for abdominal decompression anticipated by Heyns OS [15]. The device was a sealed chamber superimposed on the patient's abdomen and a vacuum pump for the local depositing. Noteworthily, the history of abdominal decompression is a typical example in the history of medical innovations: the description of the phenomena, its silencing, the rediscovery of the previously described phenomena, skepticism in relation to already known facts and its subsequent acceptance. The initial studies were carried out decades ago before the standard use of Doppler ultrasound as a diagnostic tool; consequently, the practical implementation of such method was ahead of the development of its theoretical justification.

Only two studies on abdominal decompression are recorded in the Cochrane Database. One of them states that there is no benefit from the prophylactic use of abdominal decompression in healthy pregnancies [16]. On the contrary, in the second one including pregnant women having preeclampsia a positive therapeutic effect was demonstrated [17]. Several studies have shown the effectiveness of NEXAP in reducing not only IAP, but also intracranial and pleural pressure with subsequent improvement of lung volumes and chest elasticity [18-20]. NEXAP is simple and easy to apply to the patient, but the common drawback for the NEXAP devices is the occasional incompatibility between the dimensions of the chamber and patient's anatomy.

A modern equipment for abdominal decompression (KAD01-ACS known as "The hope") have been developed in St. Petersburg (Russia) to avoid these drawbacks. The experience using this equipment showed the high efficiency of NEXAP in the treatment of different women's reproductive health conditions [21-25]. Considering OHSS as a polycompartmental syndrome, NEXAP may be used in its treatment as early as possible to prevent further organ dysfunction and to avoid the transition to a severe stage of IAH and ACS. NEXAP is a promising option in the pathogenetic treatment of IAH, but so far it has not been used in the treatment of OHSS. In spite of the benefits showed in the initial studies, there are a large number of emerging questions that embrace the safety of NEXAP methods, the need to implement continuous monitoring of IAP, the difficulty in measuring or calculating $\mathrm{Cab}$, the possible discrepancy between the IAP markers and the real IAP; the severity of OHSS at which NEXAP should be indicated, the question of the negative pressure and others related to the procedure itself as how is the best NEXAP scheme (intermittent, continuous, how many times a day,...) and how long the effect of the procedures will last. All these issues are grounds for future research in this area.

\section{References}

1. Waele DJJ, Laet DI, Malbrain ML (2016) Understanding abdominal compartment syndrome. Intens Care Med 42(6): 1068-1070.
2. Muturi A, Ndaguatha P, Ojuka D, Kibet A (2017) Prevalence and predictors of intra-abdominal hypertension and compartment syndrome in surgical patients in critical care units at Kenyatta National Hospital. BMC Emerg Med 17(1): 10.

3. Cil T, Tummon IS, House AA, Taylor B, Hooker G, et al. (2000) A tale of two syndromes: ovarian hyperstimulation and abdominal compartment. Hum Reprod 15(5): 1058-1060.

4. Lobo C, Twigg S (2010) Ovarian hyperstimulation syndrome-the role of intra-abdominal pressure monitoring. JICS 11(3): 190-191.

5. Marak CP, Chopra A, Alappan N, Ponea AM, Guddati AK, et al. (2013) Ovarian Hyperstimulation Syndrome as an Etiology of Obstructive Uropathy. Case Rep Obstet Gynecol p. 653704.

6. Marshalov DV, Salov IA, Petrenko AP, Shifman EM, Saljukov RR, et al. (2013) Effect of intra-abdominal hypertension on the outcomes of ovarian hyperstimulation syndrome. Anesteziologija i reanimatologija 6: 42-47.

7. Makino H, Furui T, Shiga T, Takenaka M, Terazawa K, et al. (2017) Management of ovarian hyperstimulation syndrome with abdominal compartment syndrome, based on intravesical pressure measurement. Reproductive Medicine and Biology 16(1): 72-76.

8. Malbrain LNG, Cheatham ML, Kirkpatrick A, Sugrue M, Parr M, et al (2006) Results from the International Conference of Experts on Intraabdominal Hypertension and Abdominal Compartment Syndrome. Intensive Care Med 32(11): 1722-1732.

9. Lincoln SR, Opsahl MS, Blauer KL, Black SH, Schulman JD, et al. (2002) Aggressive outpatient treatment of ovarian hyperstimulation syndrome with ascites using transvaginal culdocentesis and intravenous albumin minimizes hospitalization. J Assist Reprod Genet 19(4): 159-163.

10. Levin I, Almog B, Avni A, Baram A, Lessing JB, et al. (2002) Effect of paracentesis of ascitic fluids on urinary output and blood indices in patients with severe ovarian hyperstimulation syndrome. Fertil Steril 77(5): 986-988.

11. Abuzeid M, Warda H, Joseph S, Corrado MG, Abuzeid Y, et al. (2014) Outpatient Management of Severe Ovarian Hyperstimulation Syndrome (OHSS) with Placement of Pigtail Catheter. Facts Views Vis Obgyn 6(1): 31-37.

12. Maslovitz S, Jaffa A, Eytan O, Wolman I, Many A, et al. (2004) Renal blood flow alteration after paracentesis in women with ovarian hyperstimulation. Obstet Gynecol 104(2): 321-326.

13. Keulenaer DB, Regli A, Laet DI, Roberts D, Malbrain ML, et al. (2015) What's new in medical management strategies for raised intraabdominal pressure: evacuating intra-abdominal contents, improving abdominal wall compliance, pharmacotherapy, and continuous negative extra-abdominal pressure. Anaesthesiol Intensive Ther 47(1): 54-62.

14. Kirkpatrick AW, Sugrue M, McKee JL, Pereira BM, Roberts DJ, et al. (2017) Update from the Abdominal Compartment Society (WSACS) on intra-abdominal hypertension and abdominal compartment syndrome: past, present, and future beyond Banff 2017. Anaesthesiol Intensive Ther 49(2): 83-87.

15. Heyns OS (1959) Abdominal decompression in the first stage of labour J Obstetr Gynecol 66(2): 220-228.

16. Hofmeyr GJ, Kulier R (2012) Abdominal decompression in normal pregnancy. Cochrane Database Syst Rev (6): CD001062.

17. Hofmeyr GJ (2012) Abdominal decompression for suspected fetal compromise/pre-eclampsia. Cochrane Database Syst Rev 13(6): CD000004.

18. Sugerman HJ, Felton III WL 3rd, Sismanis A, Saggi BH, Doty JM, et al. (2001) Continuous negative abdominal pressure device to treat pseudotumor cerebri. Int J Obes Relat Metab Disord 25(4): 486-490. 
19. Valenza F, Bottino N, Canavesi K, Lissoni A, Alongi S, et al. (2003) Intraabdominal pressure may be decreased non-invasively by continuous negative extra-abdominal pressure (NEXAP). Intensive Care Med 29(11): 2063-2067

20. Valenza F, Irace M, Guglielmi M, Gatti S, Bottino N, et al. (2005) Effects of continuous negative extra-abdominal pressure on cardiorespiratory function during abdominal hypertension: an experimental study. Intensive Care Med 31: 105-111.

21. Repina MA, Novikov BN, Romanova LA, Gaidukova IR (2001) Clinical experience with abdominal decompression in pregnant women. Obstetrics and Women's Diseases 4: 64-66.

22. Atlasov VO, Gaydukov SN, Prokhorovich TI (2007) Current trends in improving perinatal care in obese women. Obstetrics and Women's Diseases L6(4): 46-51.
23. Vinogradov MV, Klyus OS (2010) Non-drug approaches to the prevention and treatment of pre-eclampsia. Medicine without drugs 1: $9-10$.

24. Sedletskaya NN, Sedletskaya EY, Yurkov IV (2010) Abdominal decompression in the treatment of fetal hypoxia. Medicine without drugs 1: 65-66.

25. Borovkova LV, Voronina ID (2012) Abdominal decompression in the prevention of placental insufficiency in pregnant women with anemia. Med Almanac 5(24): 33-34.

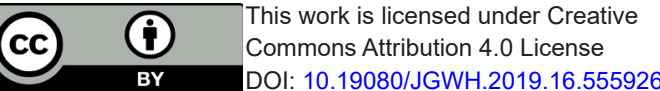

\section{Your next submission with Juniper Publishers will reach you the below assets}

- Quality Editorial service

- Swift Peer Review

- Reprints availability

- E-prints Service

- Manuscript Podcast for convenient understanding

- Global attainment for your research

- Manuscript accessibility in different formats ( Pdf, E-pub, Full Tsext, Audio)

- Unceasing customer service

Track the below URL for one-step submission https://juniperpublishers.com/online-submission.php 